\title{
Knowledge, Attitude and Practice of Breastfeeding in a Rural Community of Bankura District, West Bengal, India
}

\author{
Abhay C. Pal ${ }^{1}$, Dipta K. Mukhopadhyay ${ }^{2}$ \\ 1. Associate Professor Department of Pediatric Medicine; B.S. Medical College, Bankura-722102, West Bengal, \\ India. \\ 2. Associate Professor Department of Community Medicine; B.S. Medical College, Bankura-722102, West \\ Bengal, India. \\ Address for Correspondence \& reprint request-DR. ABHAY CHARAN PAL, SUBHANKAR SARANI (EAST), \\ P.O. \& DIST:- BANKURA, W.B. INDIA, PIN- 722101
}

\begin{abstract}
A community-based, cross-sectional observational study was conducted during August 2013 November 2013 to assess breastfeeding practices in Bankura District, West Bengal, India. In total 350 women were selected for the study. Among them $70.8 \%$ were found to be full breastfeeders, $24 \%$ were mixed breastfeeders ( mixed feeders) and 5.2\% were found to be practicing only artificial feeding ( formula and animal milk ). The main factors observed in this study interfering with exclusive breastfeeding were apprehension that the breast milk was not adequate for the baby, cesarean delivery and neonatal hospitalization. The attitude of the study population towards exclusive breastfeeding was however found to be positive in general.
\end{abstract}

Key Words: Breastfeeding; cross-sectional study; observational study; Exclusive breastfeeding; Artificial feeding; India.

\section{Background}

Breast milk has aptly been called the life-fluid for the baby ${ }^{(10)}$. Benefits of exclusive breastfeeding need no mention ${ }^{(13)}$. Due to continuing breastfeeding promotional activities under National Program and enactment prohibiting infant feeding formula the attitude towards exclusive breastfeeding has undergone a positive change in last three to four decades ${ }^{(1-3)}$. However according to recent datas the prevalence of exclusive breastfeeding among children of less than six months of age hardly exceeds $50 \%$ with significant regional variations, of course ${ }^{(2)}$. The main obstacle in raising the exclusive breastfeeding rate is lack of awareness, false belief and customs ${ }^{(4)}$. For improving the rates of exclusive breastfeeding specific information about the beliefs and practices that influence this outcome is needed. The current study was designed to evaluate practice, knowledge and attitude to breastfeeding and to assess factors associated with breastfeeding among women in a predominantly rural and suburban community of Bankura District, West Bengal, India.

\section{Objectives}

In this background this study was planned to be undertaken with the following objectives ---

(a) To identify the socio-demographic and cultural factors influencing prevalence of breastfeeding practices.

(b) To assess the knowledge, attitude and perception regarding breastfeeding.

\section{Materials and methods}

A cross-sectional observational study was conducted between August 2013 to November 2013, among women residing in Sanabandh Sub centre, Bankura I Community Development Block, West Bengal. Considering the prevalence of exclusive breastfeeding rate of 57.1\% (as reported by Sinhababu et al for Bankura) ${ }^{(1)}, 95 \%$ confidence level, $10 \%$ relative precision and $15 \%$ non-response rate, the final sample size yielded was 335 .

Weighted sample according to the population was calculated for each of the six villages of the sub centre. With a random start from the centre of each village consecutive households were visited to select the study population. All children of the last household were included. So the final sample size was 350 .

The data was collected by trained Health Assistant (female) [HA(F)], ICDS workers and Traditional Birth Attendants (TBA). They were trained the interview techniques. Informed consents were obtained from all participants. The study was approved by the institutional ethics committee of B S Medical College, Bankura. 
A structured questionnaire was used for the study. It covered demographic variables including mothers' age, mothers' education, mothers' employment status, number of siblings, mode of delivery and history of neonatal hospitalization.

Breastfeeding was divided into three types : full breastfeeding which included exclusive breastfeeding for a duration of six months (exclusive breastfeeding when no other liquid or solid from any other source except medicines or water along with medicines, enters the infant mouth); mixed breastfeeding (mixed feeding) when infant received both artificial formula and/or animal milk along with breastfeeding; and exclusive artificial feeding when infant received only artificial formula and animal milk feeding after two weeks of life ${ }^{(5)}$.

All mothers were asked questions regarding their main reasons for breastfeeding or artificial feeding (formula/animal milk). Question with modified five point Linkert rating scale from strongly disagree to strongly agree were used to assess the women's knowledge and perception regarding breastfeeding. Items testing knowledge included recommended breastfeeding duration, its' benefit in decreasing the risk of acquiring diarrhea and its role in contraception.

Questions that evaluated mothers attitude and perception regarding breastfeeding included mothers comfort with breastfeeding, cost, effect on care of other family members and effect on marital relationship.

Items that tested community's attitude towards breastfeeding included role of community nurses and medical staffs including doctors in encouraging breastfeeding, duration of maternity leave and facilities for breastfeeding at workplaces.

Data processing and statistical analysis was done using Microsoft Office Excel 2003. Variables were described using frequency distribution for categorical variables and mean and standard deviation for continuous variables. The distribution of infant feeding practices by independent variables was tested using Chi-Square test. The association between discontinuation of breastfeeding and socio-demographic, cultural characteristics of the mother was examined using suitable univariate analysis.

\section{Results}

Participant Characteristics : The age of participant mothers ranged between 18 and 37 years with a mean age of $26.7+4.1$ years. The average monthly family income was Rs. $4605.5+1662.3$ per month. About $73 \%$ of women were housewives and $44.6 \%$ had a high school degree or more. A total of 82 women (23.4\%) had two or more children (Table-1).

Table I : Participants socio-demographic characteristics and type of delivery [ $n=350$ ] :

\begin{tabular}{|c|c|c|}
\hline & $\mathrm{n}$ & $\%$ \\
\hline \multicolumn{3}{|l|}{ Age ( Year) } \\
\hline$<30$ & 232 & 66.3 \\
\hline$\geq 30$ & 118 & 33.7 \\
\hline \multicolumn{3}{|l|}{ Mothers' Education } \\
\hline Less than high school & 194 & 55.4 \\
\hline High school or higher & 156 & 44.6 \\
\hline \multicolumn{3}{|l|}{ Paid Employment } \\
\hline Housewife & 257 & 73.4 \\
\hline Employed & 93 & 26.6 \\
\hline \multicolumn{3}{|l|}{ Number of children } \\
\hline$<2$ & 268 & 76.6 \\
\hline$\geq 2$ & 82 & 23.4 \\
\hline \multicolumn{3}{|l|}{ Type of Birth } \\
\hline Vaginal & 301 & 86.0 \\
\hline Cesarean section & 49 & 14.0 \\
\hline \multicolumn{3}{|l|}{ Neonatal Hospitalization } \\
\hline Yes & 46 & 13.1 \\
\hline No & 304 & 86.9 \\
\hline
\end{tabular}

Type of feeding by socio-demographic and maternal characteristics : Of the 350 interviewed mothers $70.8 \%$ were full breast feeders, $24 \%$ were mixed breast feeders (mixed feeders) and $5.2 \%$ were practicing only artificial (formula and animal milk) feeding. Of the full breastfeeding group 68\% continued breastfeeding for more than one year. The types of feeding by socio-demographic and maternal characteristics are shown in Table 
- II. It was found that younger mothers were more likely to breastfeed. Working mothers, mothers having delivered by cesarean section and mothers of those neonates who had history of neonatal hospitalization were less likely to fully breastfeed. Mothers with higher level of education were found to practise exclusive breastfeeding more frequently.

Table II : Type of feeding by socio-demographic and maternal characteristics :

\begin{tabular}{|c|c|c|c|c|}
\hline \multicolumn{5}{|c|}{ Type of Feeding } \\
\hline & Breastfeeding & Mixed Feeding & $\begin{array}{c}\text { Infant formula } \\
\text { feeding }\end{array}$ & $P=$ Value \\
\hline & $\mathrm{n}(\%)$ & $\mathrm{n}(\%)$ & $\mathrm{n}(\%)$ & \\
\hline \multicolumn{5}{|l|}{ Mother's age : } \\
\hline$<30$ years & $182(78.5)$ & $40(17.2)$ & $10(4.3)$ & Chi-square $=19.621$ \\
\hline$\geq 30$ years & $66(55.9)$ & $44(37.3)$ & $8(6.8)$ & $P=0.000055$ \\
\hline \multicolumn{5}{|l|}{ Mothers' education: } \\
\hline Less than High school & $127(65.5)$ & $51(26.3)$ & $16(8.2)$ & Chi-square $=10.894$ \\
\hline High school or higher & $121(77.6)$ & $33(21.1)$ & $2(1.3)$ & $\mathrm{P}=0.004$ \\
\hline \multicolumn{5}{|l|}{$\begin{array}{c}\text { Mothers' } \\
\text { Occupation: }\end{array}$} \\
\hline Housewife & $192(74.7)$ & $55(21.4)$ & $10(3.9)$ & Chi-square $=7.694$ \\
\hline Employed & $56(60.2)$ & $29(31.2)$ & $8(8.6)$ & $\mathrm{P}=0.021$ \\
\hline \multicolumn{5}{|l|}{ Number of children: } \\
\hline$<2$ & $198(73.9)$ & $60(22.4)$ & $10(3.7)$ & Chi-square $=7.146$ \\
\hline$\geq 2$ & $50(60.9)$ & $24(29.2)$ & $8(9.9)$ & $\mathrm{P}=0.028$ \\
\hline \multicolumn{5}{|l|}{ Type of Birth : } \\
\hline Vaginal & $228(75.7)$ & $66(21.9)$ & $7(2.4)$ & Chi-square $=44.288$ \\
\hline Cesarean Section & $20(40.8)$ & $18(36.7)$ & $11(22.5)$ & $\mathrm{P}=2.42 \mathrm{E}-10$ \\
\hline \multicolumn{5}{|l|}{$\begin{array}{c}\text { Neonatal } \\
\text { Hospitalization: }\end{array}$} \\
\hline Yes & $21(45.7)$ & $13(28.2)$ & $12(26.1)$ & Chi-square $=50.321$ \\
\hline No & $227(74.7)$ & $71(23.2)$ & $6(2.0)$ & $\mathrm{P}=1.18 \mathrm{E}-11$ \\
\hline Total & $248(100.0)$ & $84(100.0)$ & $18(100.0)$ & \\
\hline
\end{tabular}

- Figures in the parenthesis indicate percentages

Seventy nine percent of women in this study reported that "Breastfeeding is better for my baby's health" as the main reason for practising full breastfeeding.

While $42 \%$ of all women reported that having insufficient milk is the main reason for bottle-feeding, $37 \%$ thought that employment is the main reason for not practising full breast feeding.

\section{Analysis of factors associated with being or not being full breast feeders :}

Older mothers ( $\geq 30$ years) were less likely to practise full breast feeding than mothers of younger age group $(<30$ years) [odds ratio $=2.77(1.73-4.77)]$. Mothers with higher education level (high school or higher) were more likely to practise full breastfeeding [odds ratio $=1.76(1.10-3.03)$ ]. Similarly working mothers were less likely to practise exclusive breastfeeding compared with housewives [odds ratio $=1.89(1.15-3.32)$ ] Mothers with one child were more likely to practise full breastfeeding compared to those having two or more children [odds ratio $=1.75(1.05-3.15)$ ]. Similarly women with cesarean delivery were less likely to practise full breastfeeding compared to those with vaginal delivery [odds ratio $=4.25(2.32-8.90)$ ], and mothers who had to hospitalize their neonates were also less likely to practise full breastfeeding than mothers of those neonates who did not have such history of hospitalization [odds ratio $=3.31(1.78-6.95)$ ]

\section{Knowledge, attitude and perception regarding breastfeeding practices :}

Regarding women's knowledge, on a scale of 100, "breastfeeding for three month is long enough" scored 37; indicating disagreement with the statement. Most women agreed with the statement that "breastfeeding is a good contraceptive method" ( $($ core $=68$ ) and that "breastfeeding decreased diarrhea" (score $=84)$. 
In this study positive attitude of the women towards breastfeeding was reflected by their thinking that breastfeeding was easier than artificial infant feeding (score $=84$ ); and it was less expensive than artificial 'formula' feeding (score $=81$ ).

Women's perception regarding breastfeeding was revealed by their thinking that it is not difficult for nursing mothers to care for the family (score $=71$ ) and also disagreement with the statement that 'breastfeeding adversely affect marital relationship' (score $=31$ ).

Overall attitude of the community towards encouraging breastfeeding over artificial feeding was unsatisfactory in this study showing a score of ' 32 '; as perceived by the mothers. However the women in this study felt that the doctors and the other health workers encouraged breastfeeding as reflected by a score of ' 74 '.

Working mothers in this study were not satisfied with the workplace facilities for practising breastfeeding. The statement that 'workplaces provide designated areas for breastfeeding' scored only 30 indicating disagreement with the statement.

The women in this study had moderate level of agreement with the statement that 'maternity leave of 3 months is long enough for breastfeeding' (score $=58$ ).

Mothers Knowledge, attitude and perception regarding breastfeeding is shown in Table - III :

Table- III : Mothers' knowledge attitude and perception regarding breastfeeding $(\mathbf{n}=\mathbf{3 5 0})$.

\begin{tabular}{|l|c|}
\hline \multicolumn{1}{|c|}{ Items } & Agreement \% * \\
\hline Three months of breastfeeding is long enough & 37 \\
\hline Breastfeeding is a good contraceptive & 68 \\
\hline Breastfeeding decreases diarrhea & 84 \\
\hline Breastfeeding is easier than 'artificial' milk feeding & 84 \\
\hline It is not difficult for breastfeeding mother to care for the family & 71 \\
\hline Breastfeeding is a good way to decreases family expenses & 81 \\
\hline Community encourages breastfeeding over infant formula feeding & 32 \\
\hline Doctors and nurses encourage breastfeeding & 74 \\
\hline Maternity leave of 3 months is long enough for breastfeeding & 58 \\
\hline Workplaces provide designated areas for breastfeeding & 30 \\
\hline
\end{tabular}

*On a 100 point scale a higher percentage score indicates higher participants agreement with the item tested.

\section{Discussion}

This cross sectional study demonstrated an initiation rate of breastfeeding of $94.8 \%$. Over $70 \%$ were full breast feeder and $24 \%$ were mixed breast feeder (mixed feeder). These rates are higher than those found in different reports published from different parts of the country and from this district as well $(1,6,12)$. This different rates of full breastfeeding may reflect a difference in the socio economic and cultural background (12, 17). In this study it is found that higher educational level had a positive impact on full breastfeeding rate. This finding was in conformity with the results of many other studies $(16,17)$.

The current study showed that factors associated with not practising full breastfeeding were cesarean delivery, neonatal hospitalization, working mothers and older mothers $(\geq 30$ years of age). Hospitals and workplaces without facilities for breastfeeding can be detrimental for breastfeeding. Some studies have showed that if working places provide 'breastfeeding friendly' environment most of the mothers can maintain a breastfeeding regimen for at least six months at rates comparable to non-working mothers $(14,16)$.

Breastfeeding should be linked to public health education for the whole community. In an American survey, $\mathrm{Li}$ et al showed that overall population approved breastfeeding in public places and that establishing work place breastfeeding policy and lactation room (in all Hospitals also) were the most acceptable mode for promoting breastfeeding (3). Consideration should be given to providing privacy to nursing mothers in both working and public places (including Hospitals) (3).

Almost $77 \%$ of participants reported that the main reason for breastfeeding was that it was 'better for their baby's health' (13). Healthcare activities that emphasize the advantages of breastfeeding over artificial feeding are the main factors encouraging this practice $(1,3,20)$.

In this study one major cause of artificial feeding was related to the mothers' concern that their milk was not sufficient (42\%). Studies throughout the world have shown that concern about milk supply is the most common reason women give for initiating artificial feeding along with breastfeeding $(3,4,15,16)$. Educating the women regarding time needed for colostrums to change to transitional milk and educating regarding ways of successful breastfeeding can play an important role in decreasing concern about milk supply $(15,16,17,19)$. 
Women in the present study reported that the community in general and the healthcare providers in particular encouraged breastfeeding. This study revealed a definite positive impact of improvement of level of education on rate of exclusive breastfeeding. Similar results are noted in some other studies also $(14,19)$.

A limitation of our study was its' cross-sectional design. For inclusion in this study limiting the child's age to a maximum of three years has diminished the risk of recall bias. Further cohort studies are needed to explore the effects of different socio-demographic parameters on breastfeeding practices and child nutrition as a whole.

\section{Conclusion}

This study showed that a high proportion of women did breastfeed for more than one year. However elderly mothers, working mothers, mothers who delivered by cesarean section and mothers whose babies needed hospitalization during neonatal period were less likely to breastfeed exclusively. It is speculated that having baby friendly hospitals and facilities for breastfeeding at workplaces may help in this regard. Above all, continuing health education and 'breastfeeding movement' will go a long way to increase the rate of exclusive breastfeeding.

\section{Competing interest}

The authors declare that they have no competing interests.

\section{Author's contribution}

Pal A. C. : Supervision of the field work, drafting the manuscript, revised it critically for important intellectual content and interpretation of data.

Mukhopadhyay D. K : Analysis and interpretation of data.

\section{Acknowledgements}

To all the Health workers concerned, of the sub-centre and Chief Medical Officer of Health (CMOH); Bankura, W.B.

\section{References}

[1]. Sinhababu A, Mukhodhyay D.K, Panja T.K, Soren A.B, Mondal N.K, Biswas A.B. Infant and young child feeding practices in Bankura district, West Bengal, India, J. Health Popul Nutr. 2010;28(3):294-99.

[2]. UNICEF report on current status of Baby Friendly Hospital Initiative [http://www.unicef.org/programme/ breastfeeding/assests/statusbfhi.pdf]

[3]. Li R, Hsia J, Fridinger F, Hussain A, Benton-Davis S, Grummer-Strawn L : public beliefs about breastfeeding policies in various settings. J. Am Dief Assoc 2004;104:1162-1168.

[4]. Binnns CW, Scott J A : Breastfeeding : Reasons for starting, reasons for stopping and problems along the way. Breastfeed Rev 2002,10:13-19.

[5]. World Health Organization, Global strategy for Infant and young child Feeding. Geneva: World Health Organization 2003. 41p

[6]. Dadhich JP, Agarwal RK. Main streaming early and exclusive breastfeeding for improving child survival. Indian pediatr 2009;46:11-7.

[7]. $\quad$ Black RE, Morris SS, Bryce J. Where and why are 10 million children dying every year? Lancet 2003;361:2226-34.

[8]. Saha KK, Frongillo EA, Alam DS, Ariffen SE, Persson LA, Rasmussen KM. Appropriate infant feeding practices result in better growth of infants and young children in rural Bangladesh. Am J Clin Nutr 2008;87:1852-9.

[9]. World Health Organization. Complementary feeding of young children in developing countries: a review of current scientific knowledge. Geneva: World Health Organization, 1998. 237 p. (WHO/NUT/98.1).

[10]. Quigley MA, Kelly YJ, Sacker A. Breastfeeding and hospitalization for diarrheal and respiratory infection in the United Kingdom Millennium Cohort Study. Pediatrics 2007;119:e837-42.

[11]. World Health Organization. Indicators for assessing infant and young child feeding practices: conclusion of a consensus meeting, held on 6-8 November 2007 in Washington DC, USA. Geneva: World Health Organization, 2008. 19p.

[12]. Roy S, Dasgupta A, Pal B. Feeding Practices of children in an urban slum of Kolkata. Indian J Cmmunity Med 2009;34:362-3.

[13]. Martines JC, Rea M, De Zoysa I. Breast feeding in the first six months: no need for extra fluids. BMJ 1992;304:1068-9.

[14]. Li L, Li S, Ali M, Ushijima H. Feeding practice of infants and their correlates in urban areas of Beijing, China. Pediatr Int 2003;45:400-6.

[15]. Bata M, Boulghourjian C, Abdallah A, Afifi R. Breastfeeding and feeding practices of infants in a developing country: a national survey in Lebanon. Publuc Health Nutr 2006; 9:313-9.

[16]. Wamani H, Astrom AN, Peterson S, Tylleskar T, Tumwine JK. Infant and young child feeding In Western Uganda: knowledge, practices and socio-economic correlates. J Trop Pediatr 2005;51:356-61.

[17]. Pandey GK, Hazra S, Vajpayee A, Chatterjee P. Breastfeeding indicators from a rural community in West Bengal. Ind J Public Health 1997;41:71-4.

[18]. Madise NJ, Mpoma MO. Child malnutrition and feeding practices in Malawi. Food Nutr Bull 1997;18:190-201.

[19]. Dobe M. Optimal infant feeding in rural areas - the missing agenda of communication needs. Indian J Public Health 2002;46:14550 .

[20]. Matthew AK, Amodu AD, Sani I, Solomon SD. Infant feeding practices and nutritional status of children in north western Nigeria. Asian J Clin Nutr 2009; 1:12-22. 